Article

\title{
Study on the Characteristics of Expander Power Output Used for Offsetting Pumping Work Consumption in Organic Rankine Cycles ${ }^{\dagger}$
}

\section{Yu-Ting Wu *, Biao Lei, Chong-Fang Ma, Lei Zhao, Jing-Fu Wang, Hang Guo and Yuan-Wei Lu}

Key Laboratory of Enhanced Heat Transfer and Energy Conservation, Ministry of Education and Key Laboratory of Heat Transfer and Energy Conversion, Beijing Municipality, College of Environmental and Energy Engineering, Beijing University of Technology, Beijing 100124, China; E-Mails: leibiao@emails.bjut.edu.cn (B.L.); machf@bjut.edu.cn (C.-F.M.); zhaolei140707@163.com (L.Z.); jfwang@bjut.edu.cn (J.-F.W.); hangguo@bjut.edu.cn (H.G.); luyuanwei@bjut.edu.cn (Y.-W.L.)

$\dagger$ An earlier version of this paper was presented at the International Heat Transfer Symposium 2014 (IHTS2014), which was sponsored by North China Electric Power University and held in Beijing, China on 6-9 May 2014.

* Author to whom correspondence should be addressed; E-Mail: wuyuting@bjut.edu.cn; Tel.: +86-10-6739-6663 (ext. 8323); Fax: +86-10-6739-2774.

Received: 24 June 2014; in revised form: 25 July 2014 / Accepted: 28 July 2014 /

Published: 31 July 2014

\begin{abstract}
The circulation pump in an organic Rankine cycle (ORC) increases the pressure of the liquid working fluid from low condensing pressure to high evaporating pressure, and the expander utilizes the pressure difference to generate work. A portion of the expander output power is used to offset the consumed pumping work, and the rest of the expander power is exactly the net work produced by the ORC system. Because of the relatively great theoretical pumping work and very low efficiency of the circulation pump reported in previous papers, the characteristics of the expander power used for offsetting the pumping work need serious consideration. In particular, the present work examines those characteristics. It is found that the characteristics of the expander power used for offsetting the pumping work are satisfactory only under the condition that the working fluid absorbs sufficient heat in the evaporator and its specific volume at the evaporator outlet is larger than or equal to a threshold value.
\end{abstract}


Keywords: organic Rankine cycle (ORC); pumping work; expander power

\section{Introduction}

The organic Rankine cycle (ORC) has great advantages in power generation utilizing low grade heat, such as industrial waste heat [1-3], solar energy [4], geothermal energy [5], and biomass energy [6]. The circulation pump, evaporator, expander and condenser are the four major components of an ORC system, and organic fluids, such as R123, R245fa, R143a and R134a, are usually adopted as working media $[1,7,8]$.

In the ORC system, the circulation pump increases the pressure of a liquid working fluid and transports it to the evaporator. After an evaporation process in the evaporator, high-pressure refrigerant vapor is produced and then used to generate work in the expander $[9,10]$. The output power of the expander should be larger than the consumed work of the circulation pump, and a portion of the expander power will be used to offset the consumed pumping work. Then the rest of the power is exactly the net work produced by the ORC system. Previous studies $[10,11]$ have found that a lower critical temperature of the working fluids leads to greater pumping work in sub-critical Rankine cycles. In traditional steam power plants, the pumping working is negligible since the critical temperature of the working fluid (water) is high. In ORCs, the situation totally changed. Because the critical temperature of the organic fluids adopted by ORCs is much lower than that of water, the pumping work not only can't be neglected, but also need serious consideration. Moreover, the efficiency of the circulation pumps in small-scale ORCs is quite low due to their very small specific speed which means a high delivery head accompanied by a very small flow rate. The reported values of the circulation pump efficiency are between 0.07 and 0.25 [10]. However, the efficiency of the circulation pumps in larger-scale ORCs might be high since the flow rate is greatly increased and the delivery head remains approximately constant compared to that in small-scale ORCs. In some literatures [12,13], the efficiency of the circulation pump was assumed to be 0.65 for simulation purposes. In conclusion, it is worthwhile to examine the characteristics of the expander power output used for offsetting the pumping work consumption in ORCs, especially when the pump efficiency is low.

There are very few published papers which focus on a comparison between the pumping work consumption and the expander power output. Pei et al. [14] created an experimental ORC system, in which a turbo expander was adopted to generate work. The shaft power was about $1 \mathrm{~kW}$ and the system efficiency achieved $6.8 \%$. However, the consumed pumping work was not taken into account. Quoilin et al. [15] built another ORC system in which a scroll expander was adopted and it produced about $1.8 \mathrm{~kW}$. However, the net efficiency was greatly limited by the poor performance of the circulation pump. In addition, Bracco et al. [16] presented an ORC testing system which employed a scroll expander. The expander power was $1.5 \mathrm{~kW}$ and the pumping work was still not reported. These are similar to the studies of Li et al. [17] and Zheng et al. [18], in which the expander power was obtained while there were no experimental results for the consumed pumping work. In conclusion, few papers have discussed both the expander power and the consumed pumping work. It is worth quoting here the introduction of the back work ratio (BWR) [10,11], which indicates the portion of the 
expander output power needed for driving the circulation pump. Previous studies have revealed that the BWR grows with increasing evaporating temperature, and it will become significantly high when the evaporating temperature gets close to the critical temperature of the organic fluids adopted [10,11].

By further examining the BWR and detailed analyses of the expansion process in ORCs, this work specifically studies the characteristics of the expander power output used for offsetting the pumping work consumption. The conclusions obtained are of great significance for both sub-critical and super-critical ORCs [19].

\section{Basic Assumptions Adopted in Analyses}

\subsection{Assumptions of the Cycle}

The configuration of the ORC system is shown in Figure 1. The circulation pump compresses a saturated liquid working fluid from its condensing pressure at State 3 to its evaporating pressure at State 4 and transports it to the evaporator. The cycle would be a super-critical or a sub-critical ORC if the evaporating pressure is higher or lower than the critical pressure of the working fluid. After an endothermic process in the evaporator, the liquid working fluid is fully or partially evaporated to State 1 and then used to generate power in the expander. The organic fluid discharged by the expander reaches State 2 and is condensed subsequently to saturated liquid at State 3 in the condenser. The circulation pump increases the pressure of the liquid and recycles it.

Figure 1. The configuration of an organic Rankine cycle (ORC) system.

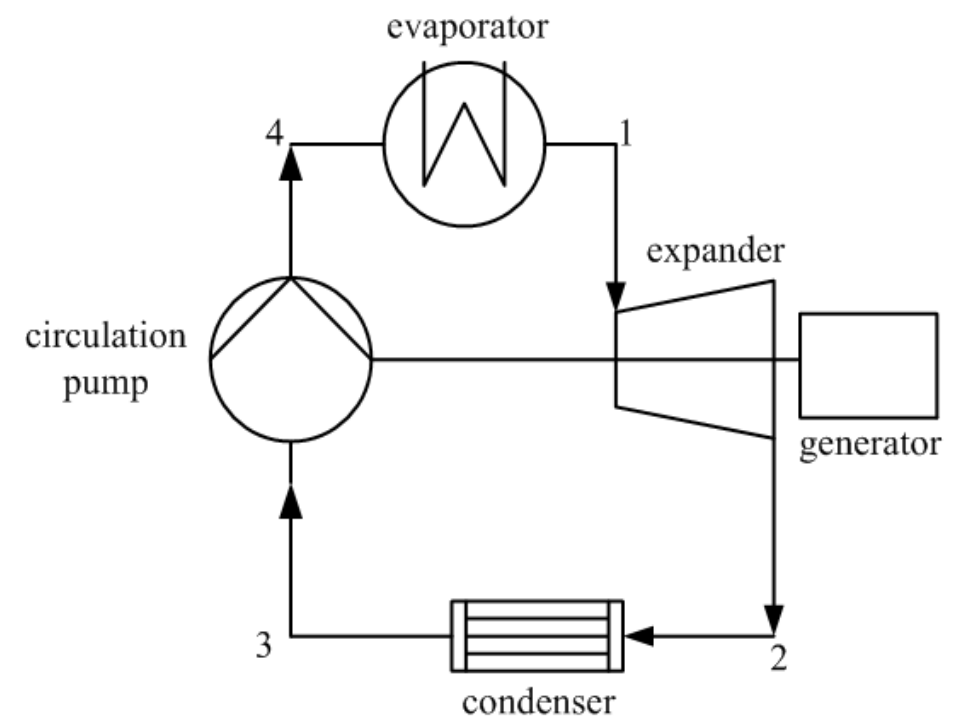

In the present paper, the pressure losses in the evaporator, condenser and pipeline are not taken into account:

$$
p_{1}=p_{4}=p_{\mathrm{v}}, p_{2}=p_{3}=p_{\mathrm{c}}
$$

where $p_{\mathrm{v}}$ is the evaporating pressure; and $p_{\mathrm{c}}$ indicates the condensing pressure.

As mentioned above, a portion of the expander power is used to offset the consumed pumping work, and the rest will be the net work produced by the ORC. Then the efficiency of the cycle can be obtained by: 


$$
\eta=\frac{w_{\mathrm{t}}-w_{\mathrm{p}}}{h_{1}-h_{4}}
$$

where $w_{\mathrm{t}}$ is the specific expander power; and $w_{\mathrm{p}}$ indicates the consumed pumping work. $\eta>0$ means that $w_{\mathrm{t}}$ is greater than $w_{\mathrm{p}}$ and the ORC can generate net work, otherwise the cycle only produces negative work.

\subsection{Specific Pumping Work}

In ORCs, the main factors affecting specific pumping work have been analyzed by Borsukiewicz-Gozdur [11]. The ORC power plant pressure range, working fluid properties, power plant arrangement and the pump efficiency all exert great influences on pumping work. The actual specific pumping work can be obtained as:

$$
w_{\mathrm{p}}=h_{4}-h_{3}
$$

The thermodynamics energy of liquid working fluid keeps invariant after the compression process in the pump because the liquid is hardly compressible. Then the pumping work is:

$$
w_{\mathrm{p}}=\frac{v_{\mathrm{p}}\left(p_{4}-p_{3}\right)}{\eta_{\mathrm{p}}}=\frac{v_{\mathrm{p}}\left(p_{\mathrm{v}}-p_{\mathrm{c}}\right)}{\eta_{\mathrm{p}}}
$$

where $v_{\mathrm{p}}$ is the specific volume of the liquid working fluid delivered by the pump; and $\eta_{\mathrm{p}}$ is the efficiency of the circulation pump.

\subsection{Specific Expander Power}

The specific expander power reaches the maximum value when the expansion process is an ideal isentropic one and the maximum value can be calculated as:

$$
w_{\mathrm{ts}}=-\int_{p_{\mathrm{v}}}^{p_{\mathrm{c}}} v_{\mathrm{ts}} \mathrm{d} p
$$

where $v_{\text {ts }}$ reflects the specific volume of working fluid in the ideal isentropic expansion process. If the irreversibility in the expansion process is taken into account, the actual specific expander power can be calculated as:

$$
w_{\mathrm{t}}=w_{\mathrm{ts}} \eta_{\mathrm{t}}=-\int_{p_{\mathrm{v}}}^{p_{\mathrm{c}}} v_{\mathrm{ts}} \mathrm{d} p \eta_{\mathrm{t}}
$$

where $\eta_{t}$ is the efficiency of the expander.

\section{Analyses on Expander Power Used for Offsetting Pumping Work}

\subsection{The BWR}

The BWR $\kappa$ is introduced to indicate the portion of expander output work needed for driving the circulation pump: 


$$
\kappa=\frac{w_{\mathrm{p}}}{w_{\mathrm{t}}}
$$

A small value of $\kappa$ denotes a cycle in which the consumed pumping working is relatively small. The expander power is capable of offsetting the pumping work and the ORC can generate net power only when $\kappa$ is less than 1 . From Equations (4) and (6):

$$
\kappa=\frac{w_{\mathrm{p}}}{w_{\mathrm{t}}}=\frac{\frac{v_{\mathrm{p}}\left(p_{\mathrm{v}}-p_{\mathrm{c}}\right)}{\eta_{\mathrm{p}}}}{-\int_{p_{\mathrm{v}}}^{p_{\mathrm{c}}} v_{\mathrm{ts}} \mathrm{d} p \eta_{\mathrm{t}}}=\frac{\frac{v_{\mathrm{p}}}{\eta_{\mathrm{p}} \eta_{\mathrm{t}}}}{\frac{\int_{p_{\mathrm{c}}}^{p_{\mathrm{v}}} v_{\mathrm{ts}} d \mathrm{p}}{\left(p_{\mathrm{v}}-p_{\mathrm{c}}\right)}}
$$

The term $v_{\mathrm{m}}$ is introduced to indicate the integral mean value of $v_{\mathrm{ts}}$, and $v_{\mathrm{t}}$ is introduced to denote $v_{\mathrm{p}}$ divided by the circulation pump efficiency and the expander efficiency:

$$
\begin{gathered}
v_{\mathrm{m}}=\frac{\int_{p_{\mathrm{c}}}^{p_{\mathrm{v}}} v_{\mathrm{ts}} d \mathrm{p}}{\left(p_{\mathrm{v}}-p_{\mathrm{c}}\right)} \\
v_{\mathrm{t}}=\frac{v_{\mathrm{p}}}{\eta_{\mathrm{p}} \eta_{\mathrm{t}}} \\
\kappa=\frac{v_{\mathrm{t}}}{v_{\mathrm{m}}}
\end{gathered}
$$

Equation (11) shows that the BWR $\kappa$ is less than 1 only when $v_{\mathrm{m}}$ is larger than the threshold value $v_{\mathrm{t}}$ and it is a criteria to determine whether the ORC is capable of producing net work. However, producing net work does not mean the characteristics of the expander power used for offsetting pumping work are satisfactory.

\subsection{The Categories of the Expansion Process}

Study on the characteristics of expander power used for offsetting pumping work needs detailed analyses of the expansion process. According to the relative size of $v_{1}, v_{\mathrm{m}}$ and $v_{\mathrm{t}}$, the expansion process can be classified into three categories. Figure 2 shows the three categories of expansion processes. In the figure, $v_{1}$ and $v_{2 \mathrm{~s}}$ are respectively used to denote the initial and the final value of $v_{\mathrm{ts}}$. Considering that $v_{\text {ts }}$ generally increases with proceeding of the expansion process, $v_{\mathrm{m}}$, which is the integral mean value of $v_{\mathrm{ts}}$, must be larger than $v_{1}$ and smaller than $v_{2 \mathrm{~s}}$.

In the expansion process of Category $\mathrm{A}, v_{\mathrm{m}}$ is smaller than $v_{\mathrm{t}}$. According to Equation (11), $\kappa$ is larger than 1. This means that the expander power is not capable of offsetting the consumed pumping work. Net work could not be obtained, and the ORC system with expansion process of this category is failure. However, this happens only in the condition of extremely low pump efficiency or very little heat absorbed by the working fluid in the evaporator. 
Figure 2. Three categories of the expansion process: (a) Category A; (b) Category B; and (c) Category C.

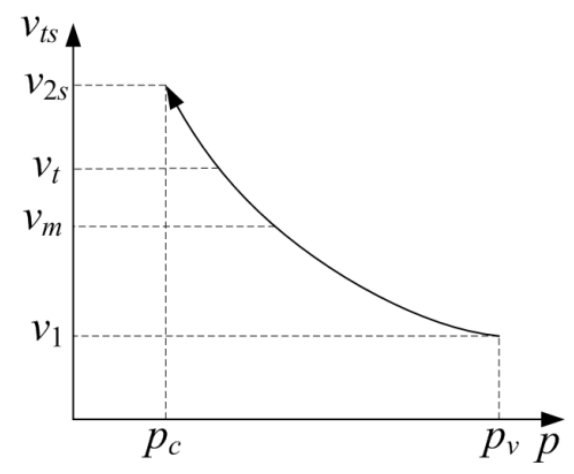

(a)

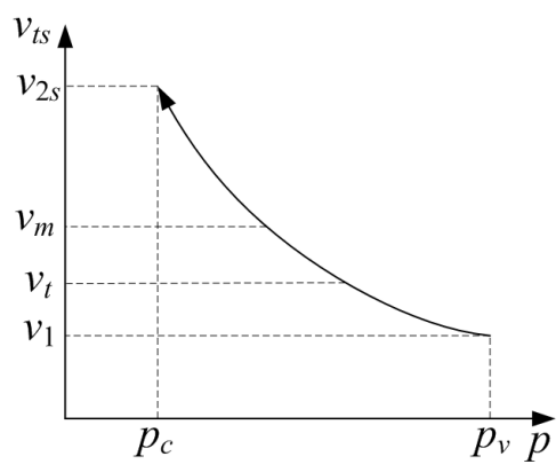

(b)

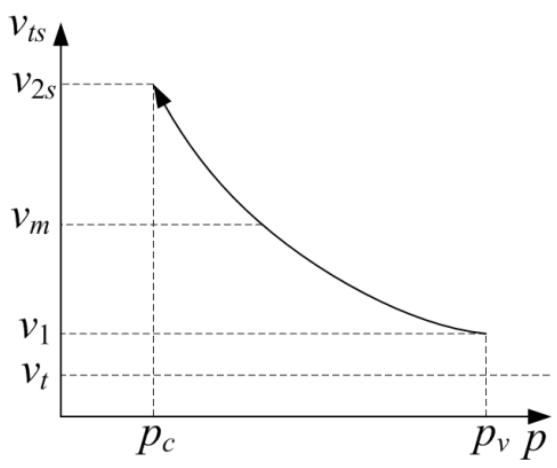

(c)

In the expansion process of Category $\mathrm{B}, v_{\mathrm{m}}$ is larger than $v_{\mathrm{t}}$, while $v_{1}$ is smaller than $v_{\mathrm{t}}$. The ideal isentropic expansion process of sub-critical ORC 1-2-3-4-1, which is shown in Figure 3 in the form of $T-s$ diagram, is of this category. Because the specific volume of working fluid at the expander inlet (State 1) is smaller than $v_{\mathrm{t}}$, state point 1 must be in upper left of $v_{t}$ isochore and probably in the two-phase region of $T$-s diagram.

Figure 3. The sub-critical ORC with expansion process of Category B.

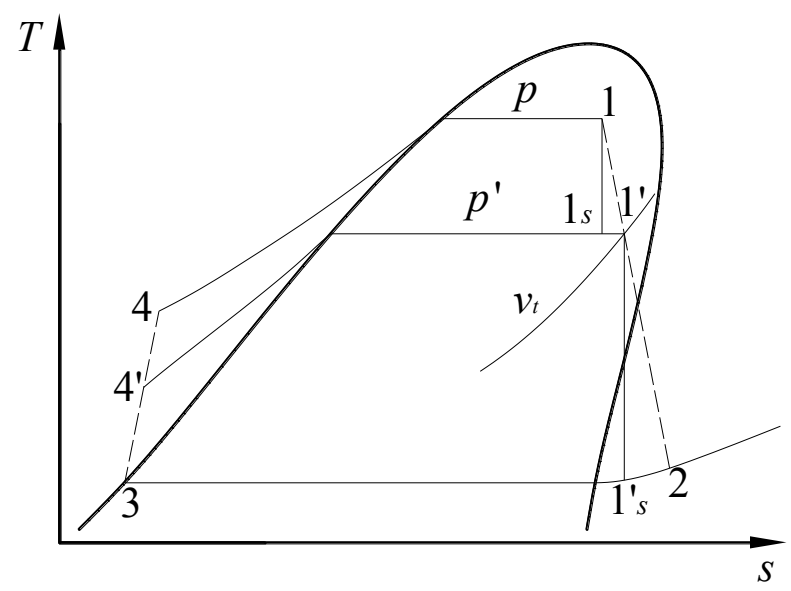

According to Equation (11), the BWR of ORC 1-2-3-4-1 with expansion process of this category is less than 1 . This means that only a portion of the expander power is used to offset the pumping work, and net work will be generated by the cycle. However, The ORC still has defects. It can be considered as an upper cycle (1-1'-4'-4-1) combined with a bottom cycle (1'-2-3-4'-1'), and the bottom cycle utilizes the heat discharged by the upper one to work. The specific volume of working fluid at State 1' is exactly $v_{\mathrm{t}}$. Because the specific volume of the liquid working fluid during the compression process in the pump keeps constant, all the three cycles have the same $v_{t}$ value if the pump efficiency and the expander efficiency in the cycles are assumed kept unchanged. Line segment $1-1_{s}$, which indicates the ideal isentropic expansion process in the upper cycle, is in upper left of $v_{t}$ isochore. Therefore, the integral mean value of $v_{\mathrm{ts}}$ in the process $1-1_{s}$ is smaller than $v_{\mathrm{t}}$. This means that the expansion process in the upper cycle is of Category A, and the power generated by the expansion process is not capable of offsetting the consumed pumping work. The upper cycle only produces negative work and it is a 
Negative Work Cycle (NWC). However, line segment 1'-1's, which indicates the ideal isentropic expansion process in the bottom cycle, is in right bottom of $v_{\mathrm{t}}$ isochore. Therefore, the value of $v_{\mathrm{ts}}$ in expansion process $11^{\prime}-1_{s}^{\prime}$ and its integral mean value are both greater than $v_{t}$. According to Equation (11), the bottom cycle is also capable of producing net power. In conclusion:

$$
\begin{aligned}
& \eta_{12341}>0 \\
& \eta_{11^{\prime} 4^{\prime} 41}<0 \\
& \eta_{1^{\prime} 234^{\prime} 1^{\prime}}>0
\end{aligned}
$$

With regard to bottom cycle 1'-2-3-4'-1', the efficiency must decrease when it is combined with the upper cycle, which is a NWC, to construct cycle 1-2-3-4-1. Then:

$$
\eta_{1^{\prime 234^{\prime}} 1^{\prime}}>\eta_{12341}
$$

Equation (15) shows that although the evaporating pressure and the evaporating temperature in ORC 1-2-3-4-1 are both higher, the efficiency is lower than that of bottom cycle 1'-2-3-4'-1'.

The situation is similar to that in super-critical ORCs. Figure 4 shows super-critical ORC 1-2-3-4-1, in which the specific volume of the working fluid at the expander inlet (State 1) $v_{1}$ is smaller than $v_{\mathrm{t}}$. It can also be considered as an upper cycle (1-1'-4'-4-1) combined with a bottom cycle (1'-2-3-4'-1'). The upper cycle is still a NWC, while the bottom cycle could generate net work. For the same reason, the efficiency of cycle 1-2-3-4-1 must be lower than that of the bottom cycle, though the evaporating pressure and working fluid temperature at the expander inlet in the combined cycle are both higher.

Figure 4. The super-critical ORC with expansion process of Category B.

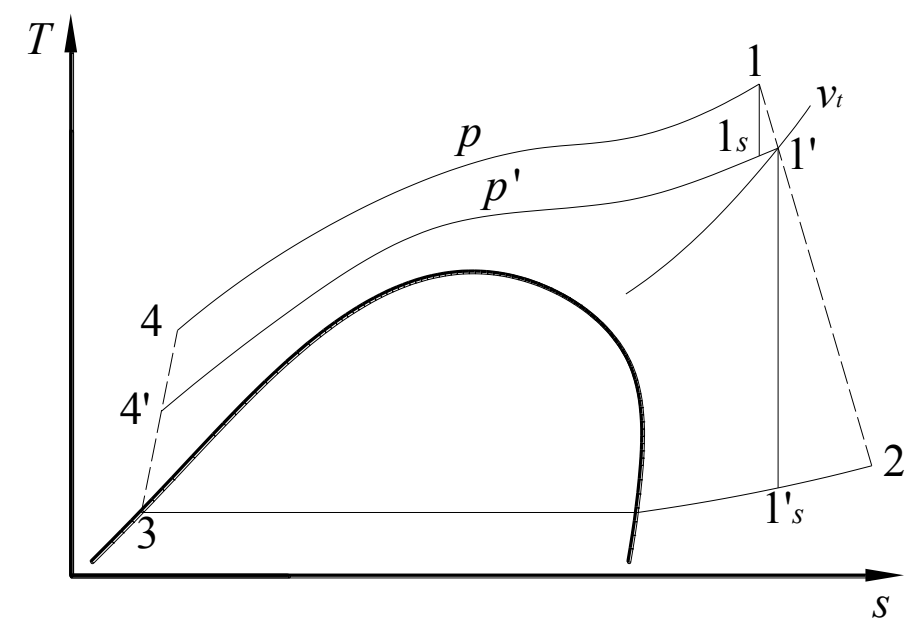

In conclusion, whether the cycle is sub-critical or super-critical, the expander power generated by the expansion process of Category B is capable of offsetting the pumping work. However, the cycle can be considered as a bottom cycle combined with an upper NWC, in which the expander output power could not offset the consumed pumping work. This causes that the ORC efficiency is lower than that of the bottom cycle, though the evaporating pressure and the maximum temperature of working fluid in the bottom cycle are both lower. Therefore the expander power, which is produced by the expansion process of Category $\mathrm{B}$, does not have satisfactory characteristics in offsetting the consumed pumping work. 
In order to avoid the occurrence of NWC and ensure that the characteristics of the expander power used for offsetting the pumping work are satisfactory, the isentropic expansion processes in ORC systems must be of Category C. In Category $\mathrm{C}, v_{1}$, the specific volume of working fluid at the expander inlet and the initial value of $v_{\mathrm{ts}}$, is greater than or equal to $v_{\mathrm{t}}$. Considering that $v_{\mathrm{ts}}$ would increase with proceeding of the expansion process, the integral mean value of $v_{\mathrm{ts}}$ is surely greater than $v_{\mathrm{t}}$ :

$$
v_{\mathrm{m}}=\frac{\int_{p_{\mathrm{c}}}^{p_{\mathrm{v}}} v_{\mathrm{ts}} \mathrm{d} p}{\left(p_{\mathrm{v}}-p_{\mathrm{c}}\right)}>v_{\mathrm{t}}
$$

According to Equation (11), the BWR of the ORC with expansion process of Category C is smaller than 1 and only a portion of the expander output power is needed to offset the consumed pumping work. Therefore, net work could be obtained from the ORC and there is no upper NWC in the cycle with expansion process of Category C. The expansion process of ORC 1'-2-3-4'-1' in Figure 3 (sub-critical condition) and Figure 4 (super-critical condition) is of this category.

From the above discussion, the conclusion could be drawn that the working fluid should be heated so that its specific volume is larger than (or equal to) the threshold value $\left(v_{t}\right)$ in the evaporator, which can ensure that the characteristics of the expander power used for offsetting the pumping work are satisfactory in both sub-critical and super-critical ORCs.

\section{Calculation Results and Analyses}

\subsection{Sub-Critical ORCs}

For traditional steam power plants, the threshold value is easily achieved. However, for ORCs, the threshold value is not so easy to achieve, especially when efficiency of the circulation pump is low. For sub-critical ORCs, in order to ensure that the specific volume of working fluid at the evaporator outlet is larger than the threshold value $v_{\mathrm{t}}$, the working fluid should absorb sufficient heat in the evaporator to make the vapor quality or superheat degree achieve certain values.

According to previous studies [15,16,20,21], here the efficiency of the expander is assumed to be 0.65 , and the circulation pump efficiency is assumed to be $0.25,0.45$ and 0.65 , respectively. Suppose that the ORC system using R245fa or R123 as working fluid is condensed at $30{ }^{\circ} \mathrm{C}$ or $50{ }^{\circ} \mathrm{C}$, Figures 5 and 6 show the minimum vapor quality required at the evaporator outlet $v s$. evaporating temperature. Table 1 gives the critical parameters of the working fluids used in calculation.

In Figures 5 and 6, it is clearly illustrated that the circulation pump efficiency exerts a great influence on the minimum vapor quality required, while the impacts of condensing temperature are minor. When the circulation pump efficiency is 0.25 , the minimum vapor quality required grows rapidly with increasing evaporating temperature, and the quality will increase to 1 as the evaporating temperature increases to about $140{ }^{\circ} \mathrm{C}$ (R245fa) or $170{ }^{\circ} \mathrm{C}$ (R123). This means that the expansion process with two-phase working fluid flowing into the expander can be adopted only when the evaporating temperature is lower than the above values. If the circulation pump efficiency is improved to 0.65 , the required vapor quality would be greatly reduced, and its variations $v s$. evaporating temperature also show a different trend especially when the evaporating temperature gets close to the critical temperature of the working fluids adopted. 
Figure 5. The minimum vapor quality required $v s$. evaporating temperature (R123).

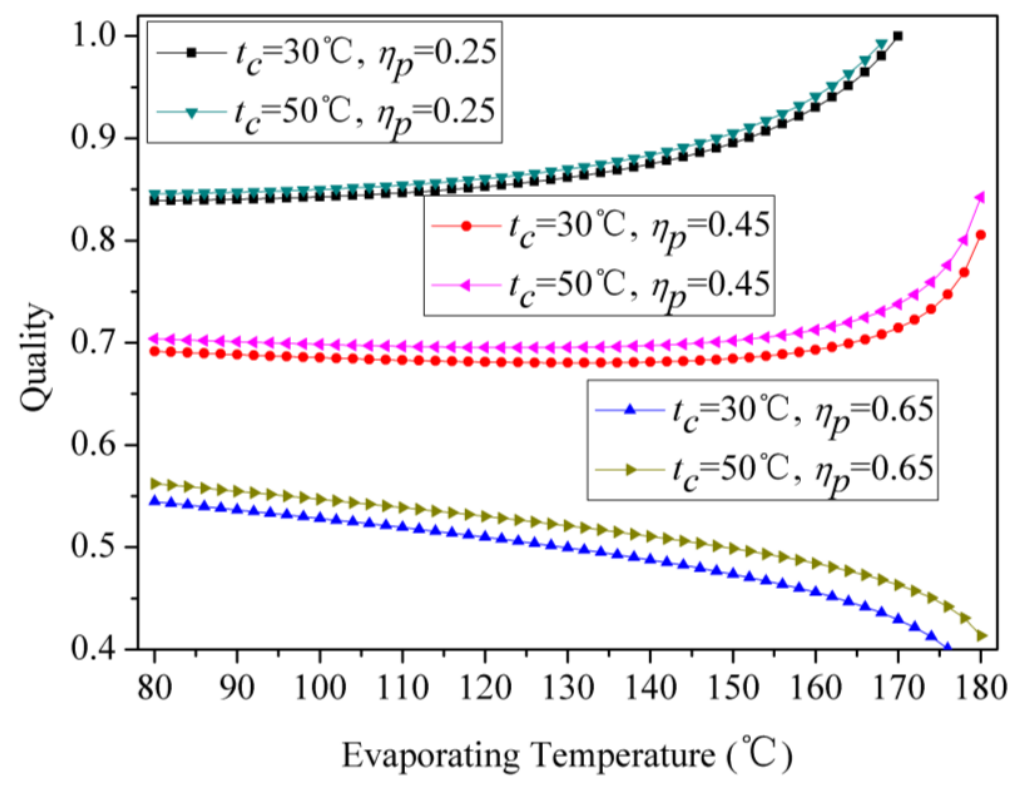

Figure 6. The minimum vapor quality required $v s$. evaporating temperature (R245fa).

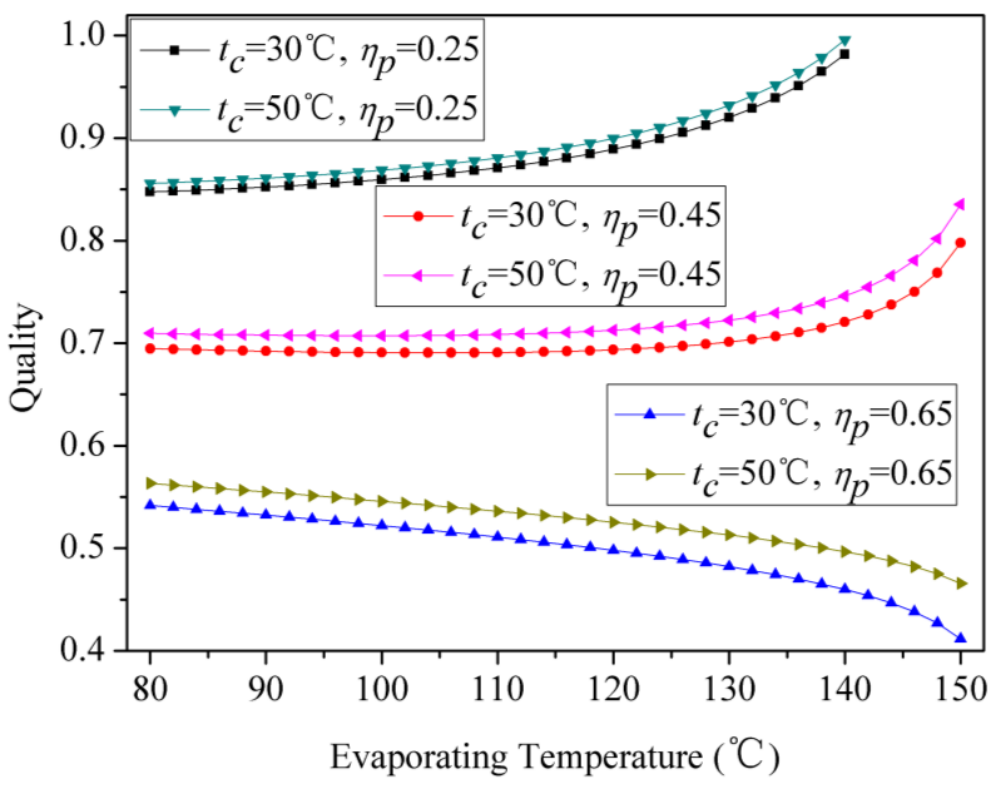

Table 1. Critical parameters of working fluids used in calculation.

\begin{tabular}{cccc}
\hline Working fluid & Critical temperature $\left({ }^{\circ} \mathbf{C}\right)$ & Critical pressure (MPa) & Critical density $\left(\mathbf{k g} \cdot \mathbf{m}^{-3}\right)$ \\
\hline R245fa (CF3CH2CHF2) & 154.1 & 3.640 & 517.1 \\
R123 (CF3CHCl2) & 183.7 & 3.662 & 550.0 \\
R134a (CH2FCF3) & 101.7 & 4.059 & 511.9 \\
R143a (CH3CF3) & 72.71 & 3.761 & 431.0 \\
\hline
\end{tabular}

The results are of great significance for sub-critical ORCs. Positive-displacement expanders in ORCs often adopt two-phase expansion process to improve the performances [7]. The intake of two-phase working fluids is helpful to block the leakage channels, and then the problem of leakage is alleviated. However, from the above discussions, in order to make the quality of the refrigerant 
vapor achieve the required value, the mass fraction of liquid working fluid at the expander inlet must be limited, or else the characteristics of the expander power used for offsetting the pumping work are not satisfactory. The results obtained in the present paper give the allowable maximum values of liquid working fluid mass fraction at the expander inlet. In addition, when the ORC operates at variable load, the pump and expander may run at different speeds. Their efficiency and the evaporating temperature of the cycle are all variable. The required vapour quality will also change subsequently. In this condition, a well-controlled system is necessary to make the vapour quality achieve the required values.

When the circulation pump efficiency is 0.25 and the evaporating temperature is higher than $140{ }^{\circ} \mathrm{C}$ (R245fa) or $170{ }^{\circ} \mathrm{C}(\mathrm{R} 123)$, in order to ensure that $v_{1}$ is larger than or equal to $v_{\mathrm{t}}$, a certain superheat degree of the working fluids at the evaporator outlet should be achieved. The minimum superheat degree required $v s$. evaporating temperature is shown in Figures 7 and 8.

Figure 7. The minimum superheat degree required $v$ s. evaporating temperature (R245fa).

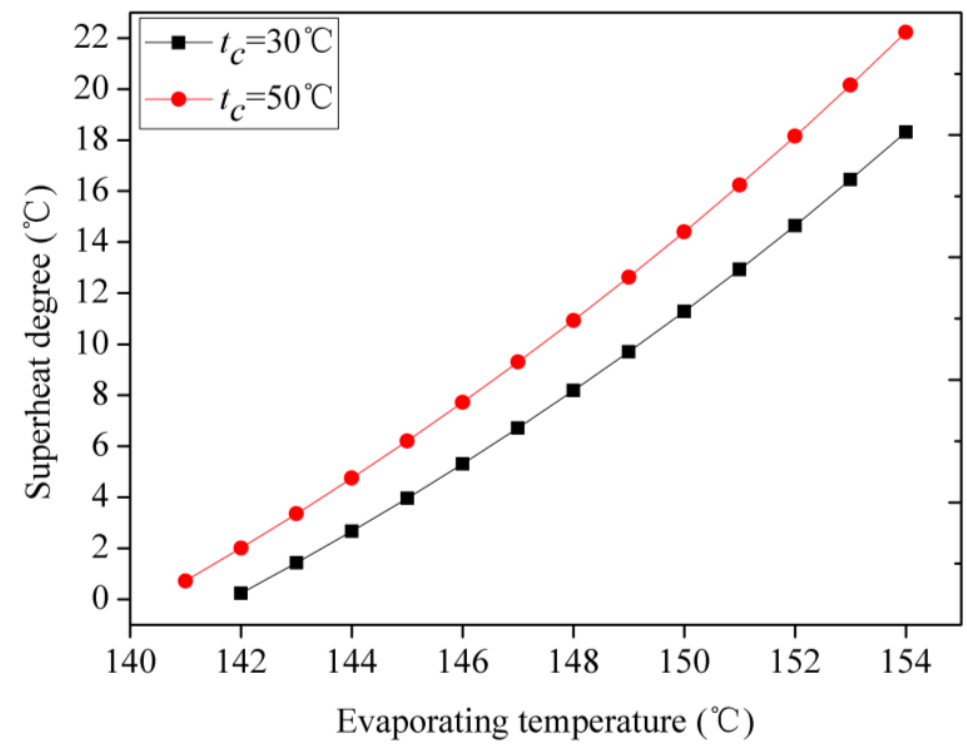

Figure 8. The minimum superheat degree required vs. evaporating temperature (R123).

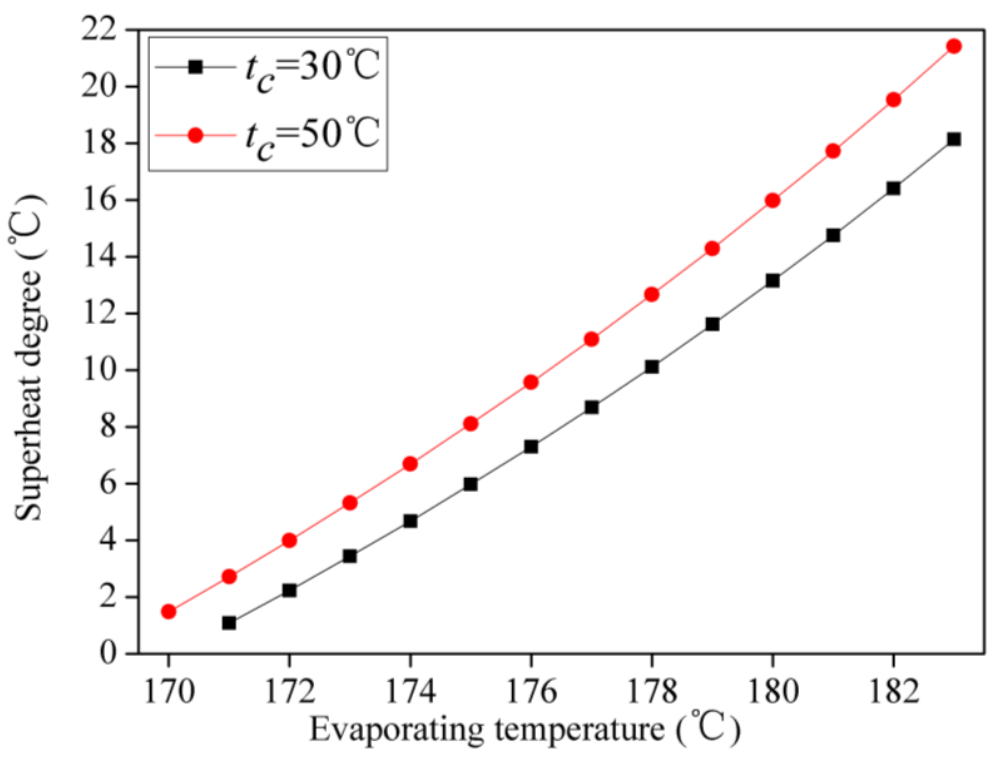


In Figures 7 and 8, it is clearly shown that the minimum superheat degree required grows approximately linearly with increasing evaporating temperature, and it would increase to about $20{ }^{\circ} \mathrm{C}$ when the evaporating temperature gets close to the critical temperature of the working fluids.

\subsection{Super-Critical ORCs}

In super-critical ORCs, the specific volume of working fluids at the evaporator outlet depends on the evaporating pressure and the maximum temperature of working fluids (at the expander inlet, evaporator outlet). In order to ensure that $v_{1}$ is larger than $v_{t}$, the evaporating pressure and the temperature of working fluids at the evaporator outlet should meet the requirement of:

$$
v_{1}=f\left(T_{1}, p_{\mathrm{v}}\right)>v_{\mathrm{t}}
$$

where $v_{1}$ is the specific volume of the working fluid when the pressure is $p_{\mathrm{v}}$; and the temperature is $T_{1}$. Equation (17) actually indicates a region below the curve of $\mathrm{f}(T, p)=v_{\mathrm{t}}$ in $p$ - $T$ diagram.

Suppose that the assumptions mentioned above are applied to super-critical ORCs using R143a or R134a (see Table 1) as working fluid, the curves of $v=\mathrm{f}(T, p)=v_{\mathrm{t}}$ are shown in Figures 9 and 10.

Figure 9. The $p$-T diagram (R143a).

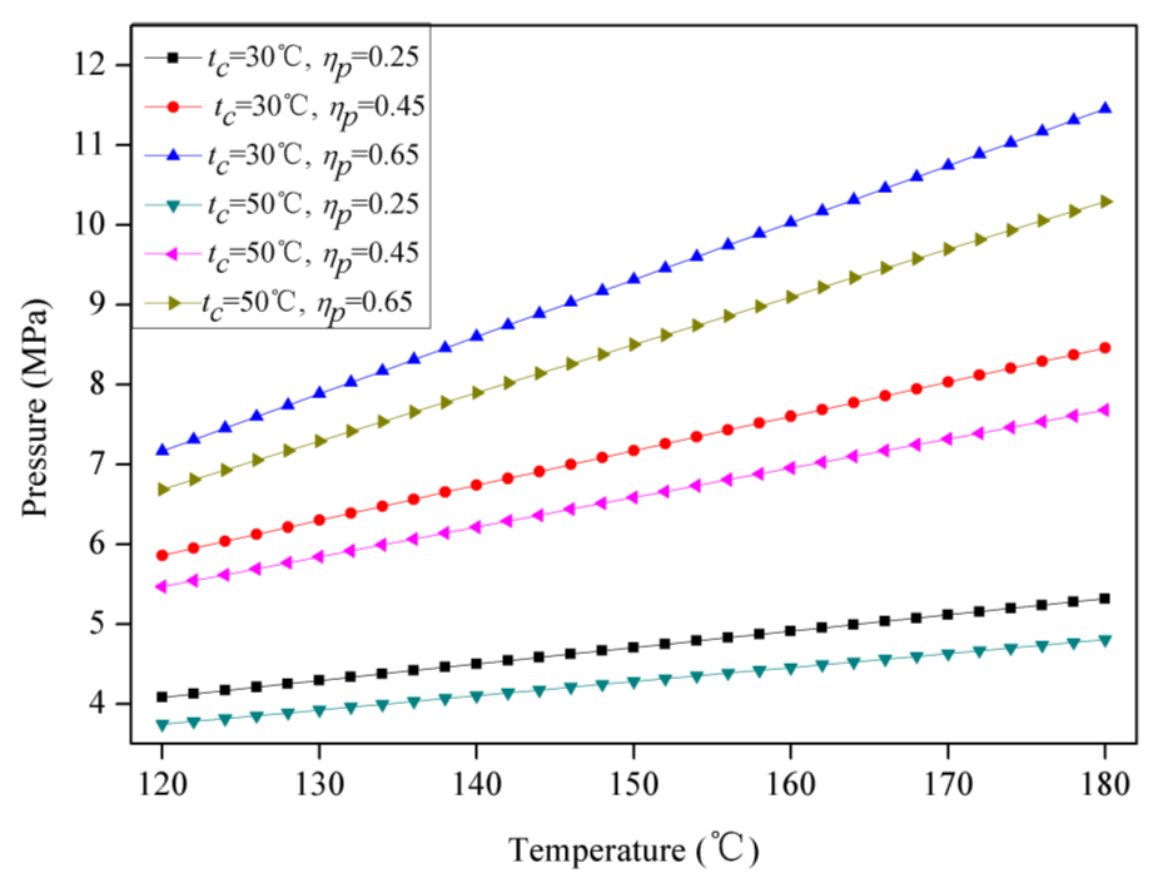

Figures 9 and 10 show that there are upper limits of evaporating pressure when the maximum temperature of working fluids is fixed at certain values, and the upper limits are rather low when the efficiency of the circulation pump is 0.25 . The Figures also illustrate that the impacts of condensing temperature are relatively small compared to that of the circulation pump efficiency.

The results are of great significance. For super-critical ORCs, increasing both the working fluids temperature at the evaporator outlet and the evaporating pressure is helpful to improve the efficiency of the cycle. However, the temperature of the working fluids is limited by that of the heat source, and cannot be increased infinitely. In this condition, neither could the evaporating pressure be increased infinitely. The results shown in Figures 9 and 10 give the upper limits of evaporating pressure. 
Figure 10. The $p$-T diagram (R134a).

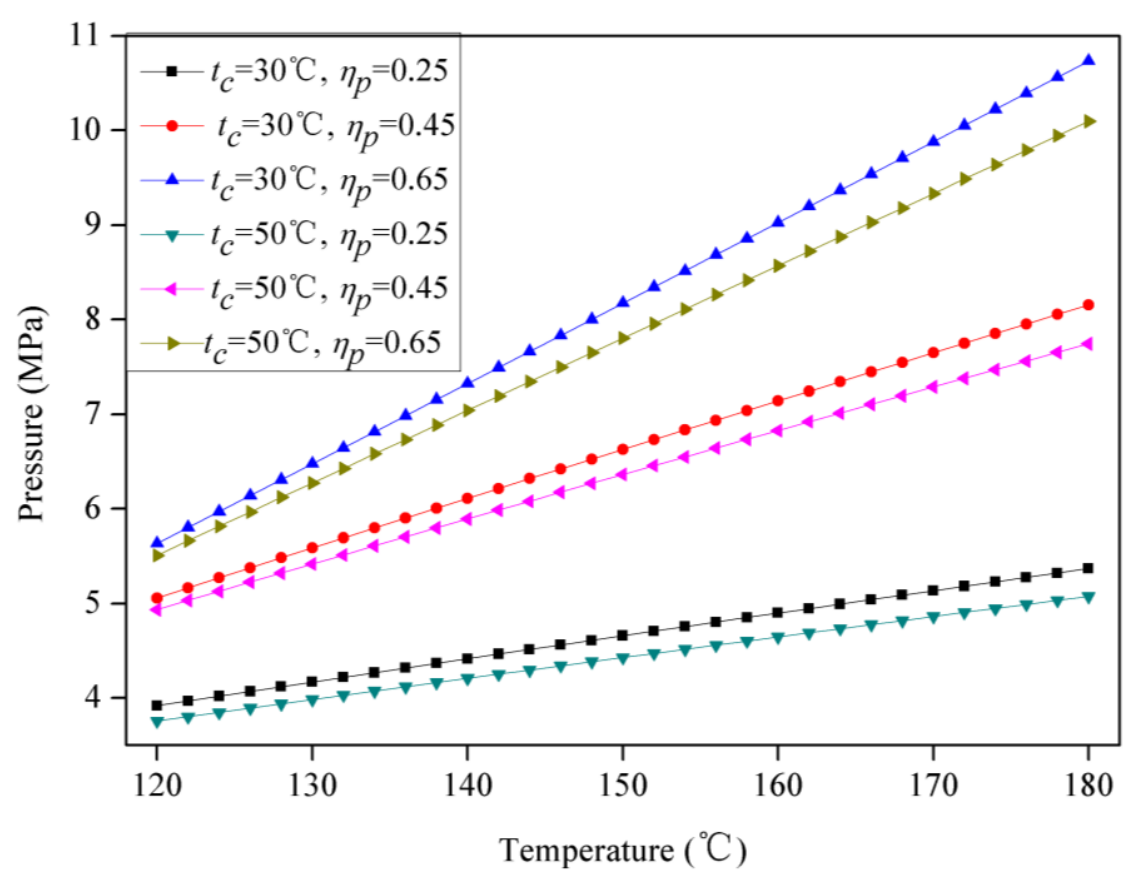

\section{Conclusions}

The present paper specifically studies the characteristics of the expander power used for offsetting the consumed pumping work in ORCs. It is found that the working fluids with specific volume larger than certain threshold values at the evaporator outlet can make the expander power output have satisfactory characteristics in offsetting the pumping work consumption. In order to ensure that the specific volume of the working fluids is large enough, the requirements of running conditions are presented for both sub-critical and super-critical ORCs. For sub-critical ORCs, although positive-displacement expanders often adopt two-phase expansion process to alleviate the problem of leakage, the liquid mass fraction of working fluids at the evaporator outlet should be limited. For super-critical ORCs, the evaporating pressure should be somewhat limited under the condition that the maximum temperature of the working fluids is fixed at certain values.

\section{Acknowledgments}

This work is supported by the National Basic Research Program of China (973 Program, Nos. 2013CB228306 and 2011CB707202) and National High Technology Research and Development Program of China (863 Program, No. 2012AA051101).

\section{Author Contributions}

Yu-Ting Wu and Biao Lei wrote the main part of the paper. Chong-Fang Ma revised the paper. Lei Zhao participated in the calculation. Jing-Fu Wang, Hang Guo and Yuan-Wei Lu gave great suggestions and polished the paper. All authors read and approve the manuscript. 


\section{Nomenclature}

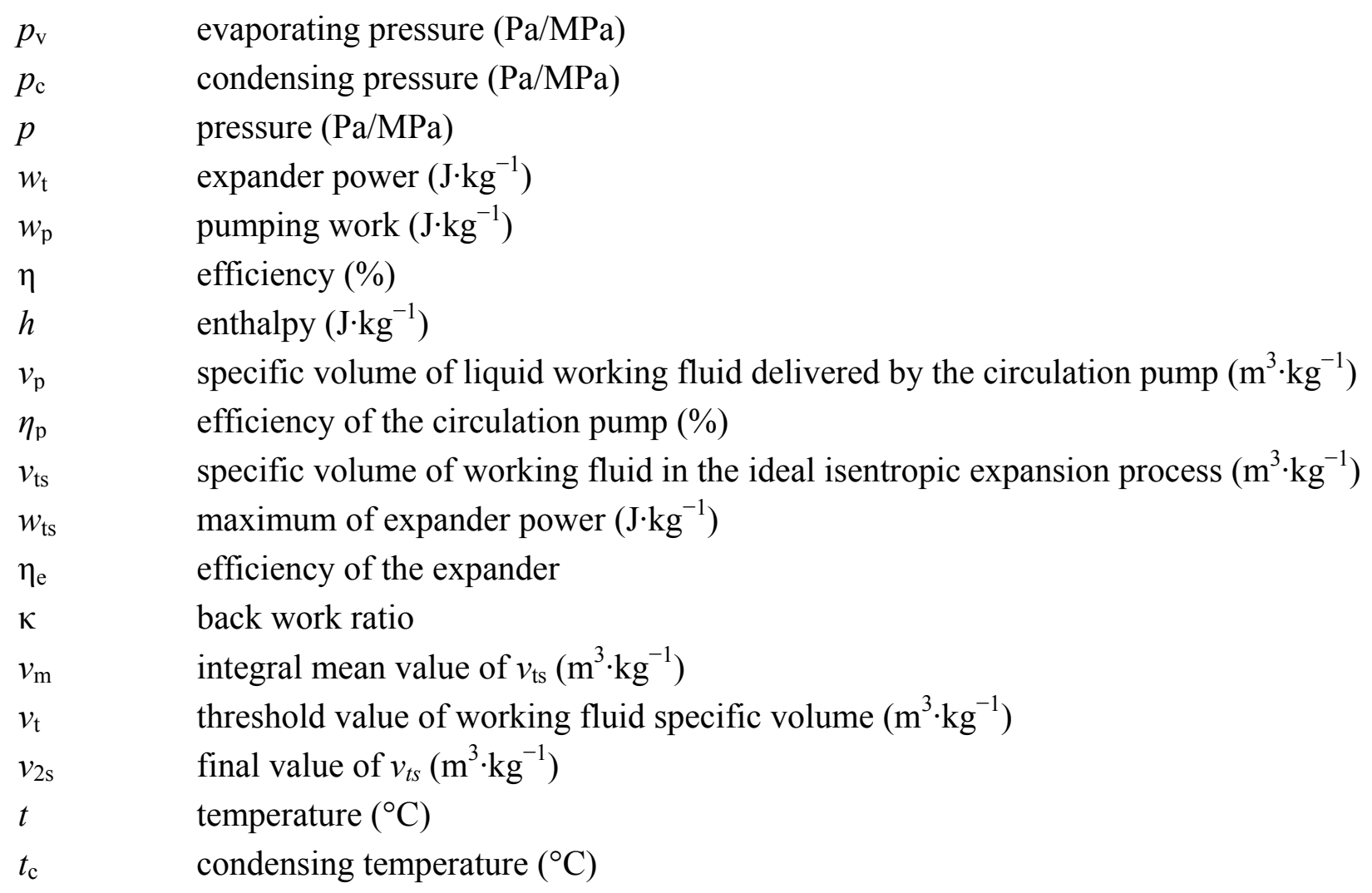

\section{Subscripts}

1, 2, 3, 4 state points in cycle (as shown in Figure 1)

$\mathrm{p} \quad$ circulation pump

$\mathrm{t}$ expander

$\mathrm{V} \quad$ evaporating

c condensing

$\mathrm{S} \quad$ isentropic

\section{Acronyms}

ORC organic Rankine cycle

BWR back work ratio

NWC negative work cycle

\section{Conflicts of Interest}

The authors declare no conflict of interest. 


\section{References}

1. Gao, H.; Liu, C.; He, C.; Xu, X.; Wu, S.; Li, Y. Performance analysis and working fluid selection of a supercritical organic Rankine cycle for low grade waste heat recovery. Energies 2012, 5, 3233-3247.

2. Sprouse, C.; Depcik, C. Review of organic Rankine cycles for internal combustion engine exhaust waste heat recovery. Appl. Therm. Eng. 2013, 51, 711-722.

3. Yang, K.; Zhang, H.; Song, S.; Yang, F.; Liu, H.; Zhao, G.; Zhang, J.; Yao, B. Effects of degree of superheat on the running performance of an organic Rankine cycle (ORC) waste heat recovery system for diesel engines under various operating conditions. Energies 2014, 7, 2123-2145.

4. Pikra, G.; Salim, A.; Prawara, B.; Purwanto, A.J.; Admono, T.; Eddy, Z. Development of small scale concentrated solar power plant using organic Rankine cycle for isolated region in Indonesia. Energy Procedia 2013, 32, 122-128.

5. Nusiaputra, Y.; Wiemer, H.-J.; Kuhn, D. Thermal-Economic modularization of small, organic Rankine cycle power plants for mid-enthalpy geothermal fields. Energies 2014, 7, 4221-4240.

6. Drescher, U.; Brüggemann, D. Fluid selection for the organic Rankine cycle (ORC) in biomass power and heat plants. Appl. Therm. Eng. 2007, 27, 223-228.

7. Bao, J.; Zhao, L. A review of working fluid and expander selections for organic Rankine cycle. Renew. Sustain. Energy Rev. 2013, 24, 325-342.

8. Chen, H.; Goswami, D.Y.; Stefanakos, E.K. A review of thermodynamic cycles and working fluids for the conversion of low-grade heat. Renew. Sustain. Energy Rev. 2010, 14, 3059-3067.

9. Qiu, G.; Liu, H.; Riffat, S. Expanders for micro-CHP systems with organic Rankine cycle. Appl. Therm. Eng. 2011, 31, 3301-3307.

10. Quoilin, S.; Broek, M.V.D.; Declaye, S.; Dewallef, P.; Lemort, V. Techno-economic survey of organic Rankine cycle (ORC) systems. Renew. Sustain. Energy Rev. 2013, 22, 168-186.

11. Borsukiewicz-Gozdur, A. Pumping work in the organic Rankine cycle. Appl. Therm. Eng. 2013, 51, 781-786.

12. Saleh, B.; Koglbauer, G.; Wendland, M.; Fischer, J. Working fluids for low-temperature organic Rankine cycles. Energy 2007, 32, 1210-1221.

13. Sauret, E.; Rowlands, A.S. Candidate radial-inflow turbines and high-density working fluids for geothermal power systems. Energy 2011, 36, 4460-4467.

14. Pei, G.; Li, J.; Li, Y.; Wang, D.; Ji, J. Construction and dynamic test of a small-scale organic Rankine cycle. Energy 2011, 36, 3215-3223.

15. Quoilin, S.; Lemort, V.; Lebrun, J. Experimental study and modeling of an organic Rankine cycle using scroll expander. Appl. Energy 2010, 87, 1260-1268.

16. Bracco, R.; Clemente, S.; Micheli, D.; Reini, M. Experimental tests and modelization of a domestic-scale ORC (organic Rankine cycle). Energy 2013, 58, 107-116.

17. Li, M.; Wang, J.; He, W.; Gao, L.; Wang, B.; Ma, S.; Dai, Y. Construction and preliminary test of a low-temperature regenerative organic Rankine cycle (ORC) using R123. Renew. Energy 2013, 57, 216-222. 
18. Zheng, N.; Zhao, L.; Wang, X.D.; Tan, Y.T. Experimental verification of a rolling-piston expander that applied for low-temperature organic Rankine cycle. Appl. Energy 2013, 112, 1265-1274.

19. Lei, B.; Wu, Y.T.; Lu, Y.W.; Guo, H.; Ma, C.F. Research on the Characteristics of Expander Output Power Used for Offsetting Pumping Work in Organic Rankine Cycles. In Proceedings of the International Heat Transfer Symposium (IHTS2014), Beijing, China, 6-9 May 2014.

20. Lemort, V.; Quoilin, S.; Cuevas, C.; Lebrun, J. Testing and modeling a scroll expander integrated into an organic Rankine cycle. Appl. Therm. Eng. 2009, 29, 3094-3102.

21. Zhou, N.; Wang, X.; Chen, Z.; Wang, Z. Experimental study on organic Rankine cycle for waste heat recovery from low-temperature flue gas. Energy 2013, 55, 216-225.

(C) 2014 by the authors; licensee MDPI, Basel, Switzerland. This article is an open access article distributed under the terms and conditions of the Creative Commons Attribution license (http://creativecommons.org/licenses/by/3.0/). 